\title{
PERAN MATAKULIAH KONSEP DASAR ILMU PENGETAHUAN ALAM DALAM MEMBEKALI KOMPETENSI CALON GURU SEKOLAH DASAR
}

\author{
Dede Trie Kurniawan \\ Fakultas Keguruan dan Ilmu Pendidikan, Universitas Swadaya Gunung Jati \\ dhe3kurniawan@gmail.com \\ Nailah Tresnawati \\ Fakultas Keguruan dan Ilmu Pendidikan, Universitas Swadaya Gunung Jati \\ Sri Maryanti \\ Program Studi Pendidikan Biologi FTK UIN Sunan Gunung Djati Bandung
}

\begin{abstract}
Abstrak
Sains merupakan badan dari ilmu pengetahuan, dibentuk dari proses inkuiri yang berlangsung terus menerus dan berkesimanbungan, dan meliputi orang-orang yang bergerak dalam bidang enterprice sains. Dari definisi di atas dapat disimpulkan bahwa ilmu sains diperoleh dari suatu proses inkuiri yang panjang dan terus menerus melalui tahapan-tahapan eksperimental. Hal utama yang membuat sains menjadi khas dari ilmu yang lain adalah sains memiliki karakteristik memerlukan proses penyelidikan dalam membangun konsepkonsep sains dengan kata lain proses inkuiri diperlukan untuk mengkontruksi ilmu pengetahuan dalam konteks sains. Upaya memajukan Sains (Dasar) yang sangat utama adalah menghasilkan pengajar Sains Dasar pada tingkat pendidikan menengah (guru) dan pendidikan tinggi (dosen) dengan pemahaman dan penyusunan bahan ajar yang baik. Bahan ajar sains untuk calon guru SD haruslah mengandung kekuatan bernalar dan kemajuan Sains terakhir. Makalah ini berupaya untuk mengungkap peran matakuliah ilmu pengetahuan alam dalam pemenuhan kompetensi calon guru sekolah dasar
\end{abstract}

Kata kunci: IPA; Kompetensi Guru SD; Mahasiswa Calon guru SD

\section{PENDAHULUAN}

Ilmu alam yang secara umum disebut juga sebagai ilmu sains memiliki karakteristik tersindiri yang membedakannya dengan ilmu sosial. Ilmu sains terdiri atas beberapa cabang ilmu. Fisika, biologi, dan kimia merupakan beberapa contoh cabang ilmu sains. Setiap cabang ilmu alam tersebut memiliki karakter yang membuat tiap cabang ilmu berbeda dan khas dari yang lainnya. Ilmu fisika, bilogi, dan kimia sebagai ilmu alam (sains) dapat dijelaskan dari hakikat sains itu sendiri. Carin (1997) dalam Rustaman (2005) mengungkapkan sains merupakan ilmu pengetahuan yang terstruktur yang diperoleh melalui proses aktif , dinamis dan eksploratif Trowbridge \& Byebee (1986) dalam widowati (2008) mendefinisikan sains sebagai berikut:
"Science is a body of knowledge, formed by a process of continuous inquiry, and encompassing the people who are enganged in the scientific enterprice" Sains merupakan badan dari ilmu pengetahuan, dibentuk dari proses inkuiri yang berlangsung terus menerus dan berkesimanbungan, dan meliputi orang-orang yang bergerak dalam bidang enterprice sains. Dari definisi di atas dapat disimpulkan bahwa ilmu sains diperoleh dari suatu proses inkuiri yang panjang dan terus menerus melalui tahapan-tahapan eksperimental. Hal utama yang membuat sains menjadi khas dari ilmu yang lain adalah sains memiliki karakteristik memerlukan proses penyelidikan dalam membangun konsep-konsep sains dengan kata lain proses inkuiri diperlukan untuk mengkontruksi ilmu pengetahuan dalam konteks sains. 
Berdasarkan pada definisi tersebut, karakteristik sains yang khas adalah sains ditempuh melalui berbagai proses penyelidikan secara berkelanjutan, yang berkontribusi dengan berbagai cara untuk membentuk sistem yang unik. Berdasarkan pada definisi tersebut, karakteristik sains yang khas adalah sains ditempuh melalui berbagai proses penyelidikan secara berkelanjutan. Sains merupakan hasil dari proses inkuiri melalui tahapan eksperimental, observasi sehingga menghasilkan konsep-konsep yang saling berhubungan satu dan yang lainnya. Inkuiri merupakan suatu proses yang sangat diperlukan dalam mengkonstruksi konsepkonsep sains. Dengan kata lain inkuiri penting untuk terapkan dalam kegiatan pembelajaran sains (Depdiknas, 2008).

Proses mengkonstruksi pengetahuan memerlukan tingkat berpikir yang tinggi. Bukan hanya sekedar menghafal dan mengingat tapi keterampilan berfikir yang lebih tinggi juga dapat dilatih melalui proses inkuiri. Berpikir tingkat tinggi ( High Order Thinking Skill ) terdiri atas beberapa keterampilan berpikir antara lain: berpikir kritis, kemampuan memecahkan masalah, berpikir kreatif, berpikir logis. Inkuiri sendiri memiliki 4 karakter yaitu, koneksi, desain, penyelidikan, dan mengkonstruksi pengetahuan. Dicermati melalui karakter inkuiri itu sendiri maka pada karakter ke empat terlihat bahwa kemampuan berpikir tingkat tinggi berpeluang untuk dapat dilatih melalui proses inkuiri.

Pembelajaran yang relevan dengan tingkat kemajuan zaman sekarang adalah pembelajaran yang berpusat pada siswa (student center). Siswa dilibatkan secara aktif dalam kegiatan pembelajaran khususnya pembelajaran berbasis inkuiri sehingga siswa dapat lebih leluasa melatih kemampuan berpikir ketika mengkonstruksi pengetahuannya sendiri. Piaget berpendapat bahwa pengetahuan pada dasarnya merupakan suatu proses. Pengetahuan bukan berupa informasi atau kepercayaan yang didapat tanpa adanya suatu proses yang di dalamnya terdapat kegiatan berpikir (Kusdwiratri, 2009).

Bertolak dari karakteristik ilmu fisika sebagai cabang sains dan teori pembelajaran konstruktivisme serta karakteristik inkuiri itu sendiri maka dalam pembalajaran hendaknya siswa dilibatkan secara aktif berinkuiri dan mengkonstruksi pengetahuannya sehingga keterampilan berpikir tingkat tinggi juga dapat dilatih dalam proses pembelajaran. Pembelajaran seperti ini diharapkan lebih bermakna bagi siswa. Menurut Ausubel (Dahar, 2011), pengetahuan yang didapat dari suatu proses pembelajaran yang bermakna yang secara aktif dikonstruksi sendiri akan tersimpan lebih lama dalam ingatan (long term memory). Dengan pengantar yang telah dijelaskan, makalah ini berupaya untuk mengungkap peran matakuliah ilmu pengetahuan alam dalam pemenuhan kompetensi calon guru sekolah dasar.

\section{PEMBAHASAN}

\subsection{Korelasi Teori Piaget Dalam Pembelajaran Fisika}

Piaget menyatakan bahwa tahap perkembangan lahir melalui beberapa proses yaitu skema, asimiliasi, akomodasi dan ekulibrasi. Proses skema yang terbentuk pada saat melakukan praktikum fisika dasar 1 dengan modul lensa ini adalah mahasiswa memiliki pandangan awal atau overview mengenai gejala alam yang terjadi di optik melalui bahan referensi yang telah dipersiapkannya. Proses asimilasi ini terjadi saat mahasiswa melakukan praktikum dengan tetap berpacuan kepada kondisi ideal yang didapatkan dari referensi yang telah dipahami sebelumnya. Mahasiswa merasa ada ketidaksesuaian antara teori yang dipahami dengan kondisi lingkungannya saat melakukan praktikum maka mahasiswa akan mengalami proses Akomodasi untuk bisa menyesuaikan informasi dari pengalaman baru yang diterima. Setelah kegiatan praktikum selelsai dilakukan maka mahasiswa akan melakukan pengolahan data, menganalisa dan menyimpulkan hasil 
praktikum yang diberikan. Pada fase ini mahasiswa akan mengalami kebimbangan karena data hasil praktikum ini ada yang tidak sesuai dengan kaidah teori. Maka akan berusaha menganalisa apa penyebabnya. Mencari korelasi hubungan antara satu besaran dan besaran lain. Saat ini lah fase ekuilibrasi terjadi pada mahasiswa tersebut.

Pieget berpendapat bahwa pada usia 11 tahun hingga dewasa proses perkembangan seseorang akan mengalami tahap operasi formal yaitu proses perkembangan dimana Pemikiran abstrak dan murni simbolis mungkin dilakukan. Masalahmasalah dapat di pecahkan melalui penggunaan eksperimentasi sistematis. Proses perkembangan ini dimungkinkan didapat melalui kegiatan praktikum.

Praktikum Fisika pada dasarnya mencari dan membuktikan hubungan antara beberapa variabel fisis melalui kegiatan pengukuran terhadap besaran-besaran fisis tersebut. Oleh karenanya kegiatan praktikum secara umum meliputi Perancangan rangkaian/susunan peralatan, Pemilihan alat ukur, Pelaksanaan pengukuran dan Analisis dan interpretasi data. Kerberhasilan Kegiatan Praktikum Fisika tergantung kepada ketepatan susunan/rangkaian peralatan, Kemampuan memilih dan menggunakan alat ukur dan kemampuan melakukan analisis data. Analisis data merupakan aktifitas mencari informasi dari sekumpulan data hasil pengukuran.

Praktikum Fisika dasar dapat mengasah dan membangun kemampuan generik mahasiswa dalam melakukan pengamatan, Pemahaman Tentang Skala, Bahasa Simbolik, Konsistensi, Logis, Inferensi Logika (Logical Inference), Logical Frame, Hukum Sebab Akibat (Causality), Pemodelan dan Abstraksi.

Mahasiswa yang melaukan praktium fisika dasar dengan modul lensa ini akan dilatih dan membangun sistematika berpikir melalui prosedural pengamatan tentang pengukuran besaran fisis berupa penentuan nilai fokus lensa dengan mengamati variable bebas berupa jarak benda dan variable terikat berupa jarak bayangan. Mahasiswa dapat meningkatkan tingkat pemahaman penggunakan alat ukur dengan skala penggunaan alat ukur yang berbeda saat pengukuran jarak bayangan. Mahasiswa akan memahami bahasa simbolik berupa persamaan penentuan fokus lensa dengan metode gauss yang telah dibantu dengan lembar kerja melalui tabel pengamatan yang diberikan. Mahasiswa dapat memprediksikan hasil jarak bayangan dengan cara membangun konsistensi logis dan inferensi logika melalui persamaan gaus secara praktikum dan membandingkannya dengan hasil teori. Serta memahami hubungan sebab akibat antara variable yang dibebaskan dan variable yang diamati. Serta dapat memodelkan hasil pengukuran dengan berupa grafik sehingga sebanyak mungkin informasi dapat diperoleh dari hasil analisa dan bentuk pemodelan yang dilakukan mahasiswa tersebut. Secara Ringkas Skema keterkaitan teori piaget dalam pembelajaran fisika dapat diilustrasikan dalam gambar berikut. 

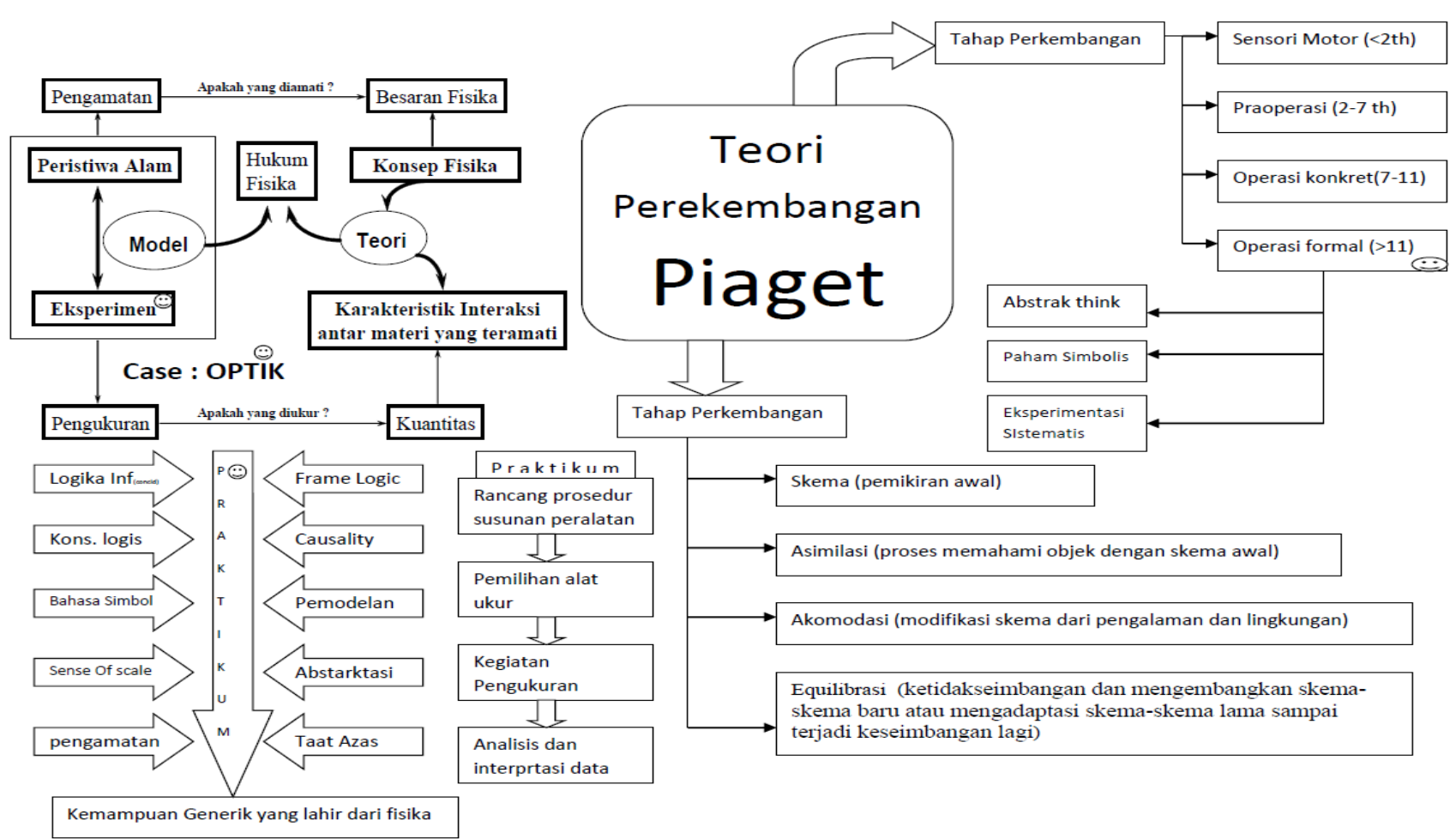

Gambar 1. Skema Keterkaitan Teori Piaget Dalam Pembelajaran Fisika

\subsection{Hakikat dan Peran Sains Dalam Pemenuhan Kompetensi Calon guru Sekolah Dasar}

Sains Dasar merupakan induk ilmu pengetahuan yang dapat digunakan manusia memenuhi kebutuhan melalui rekayasa dan teknologi. Salah satu fungsi Sains Dasar dalam pendidikan dasar, menengah dan tinggi adalah membentuk kemampuan dan pola bernalar yang sistematis, koheren dan konsisten. Kemampuan bernalar yang terasah baik akan menghasilkan generasi muda bangsa yang kreatif dan inovatif.

Upaya memajukan Sains (Dasar) yang sangat utama adalah menghasilkan pengajar Sains Dasar pada tingkat pendidikan menengah (guru) dan pendidikan tinggi (dosen) dengan pemahaman dan penyusunan bahan ajar yang baik. Bahan ajar sains untuk calon guru SD haruslah mengandung kekuatan bernalar dan kemajuan Sains terakhir.

Hakekat Pembelajaran IPA Sesungguhnya mengandung 3 aspek yaitu diantaranya Aspek Proses yang mencerminkan kemampuan siswa, Aspek Produk Yang mencerminkan Dimensi Pengethuan siswa dan Aspek Sikap yang mencerminkan Motifasi Siswa. Aspek proses bersikan kemampuan siswa dalam melakukan dugaan, pengamatan, pengukuran, penyelidikan dan penyampaian dalam mempublikasikan hasil pengamatannya. Aspek proses ini dapat mengarahkan siswa untuk memiliki keterampilan proses sains. Aspek sikap mendorong siswa agar mau tau, peduli, bertanggung jawab, jujur, terbuka dan bekerja sama. Sikap Ilmiah Inilah yang Akan dilekatkan pada siswa melalui pendidikan IPA.

Kemampuan Kerja Ilmiah merupakan Hasil belajar dari pendidikan IPA, diantaranya melakukan percobaan seperti merumuskan masalah, mengajukan dan menguji hipotesis, menentukan variable, merancang dan merakit instrument, mengumpulkan, mengolah dan menafsirkan data, menarik kesimpulan 
serta mengkomunikasikan hasil percobaan secara lisan dan tertulis. Kemampuan kerja ilmiah inilah dipandang sebagai kumpulan dari keterampilan proses. Keterampilan Proses merupakan keterampilan berpikir yang digunakan Ilmuan dalam melakukan penyelidikan ilmiah. Karena Hal inilah Tujuan Pembelajaran yang ingin dicapai dalam pembelajaran fisika diantaranya adalah Mengembangkan rasa ingin tahu, sikap positif, dan kesadaran terhadap adanya hubungan yang saling mempengaruhi antara IPA, lingkungan, teknologi, dan masyarakat dan Melakukan inkuiri ilmiah untuk menumbuhkan kemampuan berpikir, bersikap dan bertindak ilmiah serta berkomunikasi.

\section{SIMPULAN}

Belajar sains tidak hanya bertujuan memperoleh pengetahuan tetapi juga diharapkan terbentuknya nilai dan sikap berikut: kebiasaan bekerja baik (sistematis, fleksibel, imajinatif, kreatif), sikap positif (berminat, termotivasi, dan menyenangi pekerjaan), kemampuan belajar efektif (menyelidiki, memecahkan masalah, berpikir logis, rasional dan kritis, serta menghargai keteraturan dan keindahan), nilai-nilai positif atau akhlak yang baik (disiplin, jujur, efisien dan efektif, selalu mencari kebenaran). untuk mempelajarinya tidak hanya memerlukan kecerdasan intelektual saja. Agar berkembang membutuhkan kreativitas, imajinasi, estetika, akal budi, dan intuisi, dan kebenaran Dalam belajar perlu didukung kemampuan emosional (otak kanan) dan spiritual (hati), karena kemampuan intelektual (pikir) sangat dipengaruhi kemampuan emosional dan spiritual. Untuk mempelajari dengan baik perlu ada aktivitas menikmati dan merasakan, di samping aktivitas berpikir. Sains bukanlah milik golongan tertentu. Sains Untuk Semua. dan Sains milik Kita semua. Karena alam mengajarkan kebenaran, Karena Alam Wujud dari sebuah keteraturan, dan Karena Alam dapat mempertebal Iman.

\section{DAFTAR PUSTAKA}

Kusdwiratri, 1983. Teori Perkembangan Kognitif. Fakultas Psikologi Universitas Padjadjaran, Bandung, Indonesia.

Mulyana Cukup, Dkk.2004. Dikat Praktikum Fisika dasar I. Jurusan Fisika FMIPA Universitas Padjadjaran Bandung, Indonesia.

Rustaman, N. Y. (2002). Pandangan biologi terhadap proses berpikir dan implikasinya dalam pendidikan sains. Pidato Pengukuhan Guru besar. Bandung: FPMIPA UPI

Mariana, I Made Alit dan Wandi Pragnida.(2009). Hakikat IPA dan Pendidikan IPA untuk guru SD. Jakarta. PPPPTK untuk Program Bermutu

Dahar, Ratna Wilis. 2011. Teori-Teori Belajar dan Pembelajaran. Jakarta: Erlangga

Depdiknas. (2008) Strategi pembelajaran MIPA. Jakarta: Direktorat Tenaga Kependidikan Direktorat Jenderal Peningkatan Mutu Pendidik Dan Tenaga Kependidikan

Kusdwiratri. 2009. Psikologi Perkembangan. Bandung : Widya Padjajaran.

Rustaman, Nuryani. 2005. Perkembangan Penelitian Pembelajaran Inkuiri Dalam Pendidikan Sains. Dipresentasikan dalam Seminar Nasional II Himpunan Ikatan Sarjana dan Pemerhati Pendidikan IPA Indonesia

Trowbridge, L. W. \& Bybee, R. W. (1990). Becoming a secondary school science teacher (5 th edition). Columbus $\mathrm{OH}$ : Merrill Publishing Company

Widowati, Asri. 2008, Diktat Kuliah : Pendidikan Sains. Fakultas Matematika \& Ilmu Pengetahuan Alam. UNY: Tidak diterbitkan 
